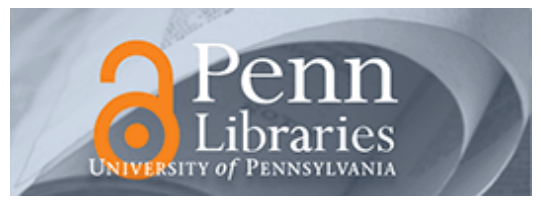

Studies in Visual Communication

Volume 10

Issue 3 Summer 1984

Article 5

1984

\title{
Ethnocriticism: Israelis of Moroccan Ethnicity Negotiate the Meaning of "Dallas"
}

Tamar Liebes

\section{Recommended Citation}

Liebes, T. (1984). Ethnocriticism: Israelis of Moroccan Ethnicity Negotiate the Meaning of "Dallas". 10 (3), 46-72. Retrieved from https://repository.upenn.edu/svc/vol10/iss3/5

This paper is posted at ScholarlyCommons. https://repository.upenn.edu/svc/vol10/iss3/5

For more information, please contact repository@pobox.upenn.edu. 
Ethnocriticism: Israelis of Moroccan Ethnicity Negotiate the Meaning of "Dallas" 


\section{Ethnocriticism: Israelis of Moroccan Ethnicity Negotiate the Meaning of "Dallas" \\ Tamar Liebes}

\section{Introduction}

The following conversation took place before, during, and after viewing an episode of Dallas entitled "Little Boy Lost," in which J. R. Ioses custody of his son to Sue Ellen, who has left him and is living with her (impotent) lover, Dusty, the scion of a competing oil dynasty. The episode is from the second season of the American television serial as broadcast in Israel, with subtitles in Hebrew and Arabic, during the winter of 1983.

Approximately fifty such conversations were taped by us in four ethnic communities in Israel (Arabs, Moroccan Jews, Russian Jews, and kibbutz members) and among nonethnic Americans in Los Angeles. The object of the study is to observe the process by which foreign audiences "decode" American television programs. The Israelis will be compared with the Americans and the several ethnic groups with one another. We are not attempting to demonstrate "effect"; rather, we are interested in those processes that are prerequisite to possible effect, namely, understanding, interpretation, and evaluation, both explicit and implicit. We wish to address the question of how American films and television programs cross cultural and linguistic frontiers so easily and to assess the extent to which foreign viewers "read" these texts in the ways that critics and content analysts assume they do. The allegation of cultural imperialism cannot be tested by content analysis alone

Each of the discussion groups consists of three married couples, friendly with one another and familiar with the program. Interviewers were trained to assemble such groups on the basis of ethnic and age homogeneity, to observe them as they view the program (off-air in Israel and on videotape in Los Angeles), and to stimulate a conversation. Interviewers were equipped with guidelines for openended questions.

Tamar Liebes is completing her doctoral dissertation at the Communications Institute of The Hebrew University of Jerusalem as part of a crosscultural study of the decoding of American television fiction. The overall project, entitled "The Export of Meaning," is directed by Professor Elihu Katz and is based jointly in Jerusalem and at The Annenberg School of Communications at the University of Southern California. Liebes is also a radio producer for KOL ISRAEL, the Israeli broadcasting authority. 
This method of focus interviews, or "constructed conversations," as William Gamson calls them, was chosen in the belief that talk about shared viewing experiences takes place naturally in society and is a key to the process by means of which program content seeps, if it does, into personalities and cultures. That people discuss Dallas in everyday situations and view it together are facts that we can certify from background data as well as from allusions in the discussion groups themselves (Lull 1980; Bryce and Leichter 1983). Whether such constructed conversations are faithful simulations of everyday conversations we cannot say for sure. In any case, Dallas seems a particularly appropriate stimulus for our purposes because of its worldwide popularity, its relative complexity, its agenda of basic values, and, not least, because it is the kind of "visual narrative" that is based-like soap opera-more on words than on action.

The participants in the conversation reported here are three Jewish couples of Moroccan origin who are by now well integrated into Israeli society and who are all good friends. With one exception the participants can all read the subtitles; they do not understand English. Adi, the interviewer, came to the home of Zehava and Yossi; two other couples - Cecile and Itzchak, and Massudi and Machluf joined them.

Even before the episode went on the air, spontaneous conversation on Dallas began, and so taping was started at once. The discussion continued during the viewing, when characters and events on the screen were sometimes incorporated into the conversation. By the time the focus discussion was due to begin, the conversation and the wine flowed quite naturally, making it difficult for Adi to stick to her moderator's role; by that time she was comfortably integrated into the group and some of the points of discussion had already been covered. There is no question in our mind that this is the way these people normally talk to one another, even if it is unlikely that they normally talk in such a sustained way about a television program or, indeed, any issue. In any case, it is a rare documentation of television talk.

This group is of particular interest, we think, because it illustrates vividly how community members "negotiate meanings" by confronting the "text" with their own tradition and their own experience. The conversation suggests that the program serves viewers as a "forum" (Newcomb and Hirsch 1983) for discussion of personal, interpersonal, and social issues (e.g., discussion of justice, notes 36,46 ; whether fathers have equal rights in their children, note 66; childrearing problems, note 58 ; sex-role differences, notes
23, 29; attitudes toward adultery and divorce, notes 2, $25,73,76)$. Note also the ways in which knowledge of the program is used as a source of status (Cecile, at note 33) just as knowledge of traditional texts conferred status; how the program functions as escape from problems such as cramped quarters (note 77 ), religious demands (note 20 ), and the harsh reality of the prolonged Lebanese campaign (note 80); and how other texts - especially religious ones - are invoked (notes 10, 24, 74, 76).

To call attention to these processes, we have annotated the protocol of the conversation and flagged each of the notes with one or more of the following subheadings that may help to clarify what is going on: (1) understanding, for coherent perception of the story line; (2) interpretation, on making sense of the story or of characters; (3) evalution, on the acceptance and rejection of perceived values in the story; (4) interaction, on the social dynamics of the group; (5) participation, on relating to the characters as if they were real; (6) positive and negative identification with characters; (7) acculturation, on bringing communal or traditional sources to bear on interpretation; (8) mutual aid, group interaction with respect to understanding, interpretation, or evaluation; (9) forum, on spontaneous use of the text as a springboard for discussion of personal, interpersonal, or communal problems; (10) criticism, for statements that reveal understanding of the genre or of the poetic requirements of television fiction; (11) narration, for ethnic or personal patterns of retelling the story or describing the characters; (12) gratifications, for self-defined "uses" of the program in connection with social and personal needs; and (13) methodology.

Also present, in addition to the three couples and Adi, the interviewer, were the observers, Elihu and Gil, who operated the tape recorders and made notes. The present text is slightly shortened from the full transcript. 
1 Understanding: Unlike the other participants, Massudi does not know Hebrew and is, therefore, reluctant to answer questions. There are indications that she does watch Dallas and comprehend it, such as her remark during the viewing of the program regarding J.R.'s unsuitably informal dress in court (cf. note 28), which shows that she can both understand and criticize the basic plot. This would explain why her husband fills her in at night on the more detailed Dallas gossip.

A solely visual knowledge of a TV program can lead to serious misunderstanding, especially when the visuals, which are necessarily decoded according to the viewer's culture, impart meaning that is far from the producer's encoding. Thus, another, similar viewer was surprised to learn that the beautiful "hotel" Pam was visiting was, in fact, a psychiatric hospital.

2 Interaction: The conversational pattern whereby Cecile repeatedly breaks into her husband's sentences should not necessarily be looked at as interruptions. In certain cultural settings, this constitutes what sociolinguists call "corporate sentence building" (Bennet 1978). This form of conversation characterizes cultures in which there is need for reassurance and encouragement-being "polite," therefore, means cooperating in presenting oneself and the other. This does not exist in cultures where the need for privacy and autonomy is considered crucial and, therefore, being polite consists of respecting the boundaries of each individual (Brown and Levinson 1979). Conversations in which there are frequent pauses and strict turntaking belong to the second type of politeness, as it is concerned with respect for the distance among people. The discussion of the Moroccan group under consideration here, characterized by frequent overlaps, is associated with the first type of politeness, which creates an atmosphere of intimacy. Thus, Cecile's
MACHLUF: Even when I look at it and I know it's an actor, that it's only cinema, but they act so much theater, they play it so much from their gut, especially J.R., he's great.

ADI: Do you understand what he says or do you read the subtitles?

MACHLUF: I understand what he says and what he acts and I understand him.

Yossi: She [the interviewer] means the translation [subtitles]. Do you read the translation?

MACHLUF: Of course, the translation.

ADI: Anybody here understand English?

MACHLUF: Well, unfortunately we studied French in our town, only French.

Yossi: Yes, we all read the translation.

CECILE: I was in France a month ago and I saw a few episodes. In French it was simply a pleasure. Here I enjoy it less, that is, there I discovered I enjoyed it more. Because I saw it here all the while without knowing whether I enjoy it more or less. I don't read Hebrew one hundred percent and it takes me time to read and it's a pity.

ADI: [To Massudi]: What do you think?

1 Massudi: I don't see Dallas at all.

MACHLUF: I see it for her-and in the middle of the night I tell her everything [general laughter].

CECILE: I always see it even though I get fed up. I anticipate what's going to happen and sometimes I think, well, what did I sit for? But anyway, I do sit, and watch. . .

MASSUDI: You do sit.

MACHLUF: When it's French she [Massudi] understands.

ITZCHAK: I do watch but I think what's nice about the program is its richness, the beauty.

2 CECILE: The landscape.

ITZCHAK: The landscape.

CECILE: It's rich ...

ITZCHAK: It's rich like all American movies

3 MACHLUF: The beach, the pool, the colors, the apartment.

ZEHAVA: The house.

ITZCHAK: But after a while the subject becomes a little tiring because there are unacceptable things.

MACHLUF: For example?

ITZCHAK: Things that don't happen in life, let's say things that happen in a family, all the stories.

CECIIF: They exaggerate sometimes. 
overlapping with Itzchak is probably: (1) an indication of intimacy and consensus between husband and wife; and (2) her way of joining the conversation and adding to the discussion rather than interrupting it.

3 Interpretation: As most Israelis live in apartments, Machluf slips into calling the Ewing mansion "the apartment." He is immediately corrected by Zehava who, as we later discovered, was just in the process of trying to find a way to move her own family from a two-room apartment to a slightly larger one.

4 Israel has one television channel. About half of the programs are imported from abroad, mostly from the United States. Subtitles are in Hebrew and Arabic

5 Gratification: Itzchak's comment suggests that viewing Dallas provides a different kind of experience than, say, viewing Kojak. He is, in effect, saying that the pleasure of watching does not arise from being curious about what the characters are going to do but about how they do it. Not having to worry about the technicalities of the plot, viewers can relax and enjoy following the Ewings they are so well acquainted with, whose idiosyncracies are anticipated. They thus pay attention to every deviation. For the viewers, the pleasure of seeking out and discovering all the intricate details of the TV program is similar to the pleasure of a reader in reading a novel for the second time (Barthes 1975)

6 One source of information about future developments in the story is Jordanian Television, which is one season ahead of Israeli Television.

7 Evaluation: Itzchak is raising a central moral and philosophical issue concerning the viewing of Dallas. Describing it in terms of the celebration of the success of ruthless power over moral values, of the victory of id over superego, leads him to consider whether this is a reflection of what happens in real life. Itchak's answer is negative because "normal" to him means "normative.

8 Interpretation, Forum: This leads to a discussion about the "normality" of social norms. Machluf and Zehava argue that norms are not "normal" because people, in general, are attracted by power and glamour and therefore Dallas fulfills the needs of the viewer's self-which is id, not superego.

In interpreting the program's story, they draw on knowledge of life-and vice versa: They generalize about life and this provides an interpretation of the story. Either way, they talk about Dallas as if it were real.

These generalizations about what "people" like contradict what the group members say they themselves like and identify with. They select and evaluate characters on a strictly moral basis: When they are asked to name the central characters in the episode, J.R. is not included. The difference between talking about what "they" ("people," "most women") like and what "we" (Jews, Moroccans) like shows that normative rules are still powerful when speakers feel personally responsible for their statements. In Newcomb's (1984) terms, they might be employing different or even conflicting "discourse systems" in the two cases. Whereas here they talk as if they were participant observers in informal chats about Dallas, later, in answering the interviewer's question, they define themselves in the voice of a particular social and cultural community.
ITZCHAK: It's exaggerated that they all give in to somebody like that. It's simply not real. It doesn't seem as true to life as it was at the beginning [of the serial]. After a while it starts to become boring. Even annoying.

ADI: But you see it faithfully?

CeCile: Yes, yes.

ITZCHAK: I see it for two reasons. The first reason, to our regret is that we don't

4 CECILE: We don't have programs here.

5 ITZCHAK: We don't have very good programs. The second reason is that it's done so well_-the setting and all_-it attracts one, simply that. But I think it's good they stopped showing it for a time because we became almost slaves to this subject even though I'm sure everybody knew what was going to happen.

ZEHAVA: There are also books [about Dallas]

6 CECILE: And people see it in Jordan, and it's more advanced.

ITZCHAK: It's something that almost repeats itself. The same mistakes that J.R. made repeat themselves, and it's no longer a subject for study.

ELIHU: What mistakes?

ITZCHAK: For example, when the father capitulates to J.R.'s mistakes in his business.

\section{MACHLUF: Which cost many millions}

7 ITZCHAK: And he always makes sure that he will succeed at any cost, and the women fall into his arms like I don't know what and this is something in the story which is not really normal in life.

MACHLUF: Don't forget that J.R. is very good-looking and very rich.

8 ZEHAVA: And what do people like? Money.

MACHLUF: Good-looking and rich is something which attracts many women.

CECILE: Everybody, more or less, also in the movie, knows what he's worth.

\section{ADI: What does that mean?}

MACHLUF: His character, his character

CECILE: That he is not honest in business, with women, in everything. But nevertheless, women continually .. .

MACHLUF: ... go after him.

CECILE: Anybody he wants

MACHLUF: ... gets caught in his net.

CECILE: .... fall very fast.

Yossl: Are attracted to him. 
9 Participation, Acculturation: Zichrona livracha, the traditional Jewish way of alluding to someone who has died, is used ironically in this case. It still gives a sense of how the participants chat about Dallas characters as real people who live or, as in this case, die.

10 Evaluation, Identification (negative): This is just one instance in which Machluf invokes quotations from religious sources as a way of relating to the "invading" world of television. Here a quotation is used to contrast the mores of Dallas with those of his own culture; thus, he reinforces the traditional values.

11 Participation, Interpretation, Mutual Aid: The debate over J.R. being the father of the baby points to the kind of involvement through speculation that Dallas arouses: The "facts" of the story turn out to be a matter of interpretation. Different, sometimes contradictory bits of information are brought forth as evidence for various ways of understanding the story. Machluf knows the baby is not J.R.'s and proves it with Sue Ellen's words: "She told him the truth." Cecile brings up the laboratory test as proof of the opposite. (Note the mutual aid in the interpretive process; see Katz and Liebes 1984.)

When the group returns to this argument later (cf. note 52), the problems of how to evaluate the various "facts" come up-Can Sue Ellen know for sure? Is the lab test true or "fixed?" Dallas can thus occupy viewers' minds because all solutions are partial and reversible.

12 Methodology: Taping was discontinued here on the assumption that there would be little or no conversation during the viewing. Fortunately, the observers took notes verbatim until the recording resumed.

13 Criticism: Whereas the others assumed some kind of real or objective "truth" behind what is shown on the screen, Yossi-who is not a regular viewer-talks from an uninvolved distance that enables him to analyze Dallas as a TV show rather than as a reality. As such, he places it within the genre of Arab soap operas that are popular on Israeli television. His use of the rhyming words te'una and hatuna accentuates the repetitive, formulaic nature of the plot.

14 Criticism: Here Bobby and J.R. are described as polar opposites. Later in the conversation, two other kinds of characters emerge (cf. notes 51, 52).
9 MACHLUF: Are attracted to him. Kristen, zichrona livracha [may her memory be blessed] was also attracted.

Yossl: The truth is, he's attractive, he's a goodlooking fellow.

CECILE: They don't want to believe what they hear. They love him and they don't want to accept the complaints against him. What one hears.

10 MACHLUF: You see l'm a Jew wearing a skullcap and I learned from this film to say [quoting from Psalms] "Happy is our lot" that we're Jewish. Everything about J.R. and his baby, who has maybe four or five fathers, I don't know, the mother is Sue Ellen of course, and the brother of Pam left, maybe he's the father. . . I I see that they're all bastards. Isn't that true Doctor Katz?

ELIHU: Really bastards or bastards in character?

MACHLUF: According to the movie, this son is literally a bastard. She was pregnant from Pam's brother.

11 CECILE: . . but the tests show that J.R. is the father ...

MACHLUF: ... and J.R. recognizes this himself. She told him the truth. She says: "I am pregnant from

Pamela's brother." What's his name.

ITZCHAK: BObby.

MACHLUF: No, no. Bobby is Pam's husband.

CECILE: Cliff, Cliff.

MACHLUF: Cliff.

ITZCHAK: But, in fact he [J.R.] saw that it was his son.

GIL: OK, we're beginning. The program is starting.

12 [Discussion while viewing (from observer's notes, not recorded)]

MACHLUF: There's Miss Ellie.

ITZCHAK: Miss Ellie is wonderful but the queen is Pam.

13 Yossi: It's only the second time I'm seeing Dallas. It looks like an Arabic film, begins with an accident [te'una], and ends with a wedding [hatuna].

ZEHAVA: The men see the movie because of the beautiful girls.

14 CECILE: And there's a good mother. [On screen: Miss Ellie is reprimanding J.R. because he intends to buy off the judge.] Bravo. Bobby is too good and J.R. too bad, both extremes.

Yossi: J.R. looks like Tony Curtis. 
15 Participation: Cecile's surprised comments on seeing Cliff's mother sound like those of someone meeting an al most-forgotten old acquaintance. Peripheral characters are typically identified in terms of their family relations, which viewers often have no problem understanding in spite of the complexities and interconnections of the kinship web (cf. conversation at note 11).

16 Evaluation, Forum: An illustration of how Dallas becomes a "forum" for the articulation of social issues (Newcomb and Hirsch 1984) can be found in this discussion, which starts with Itzchak pointing to the message of Dallas. Itzchak chooses to apply a moral criterion for judging characters, which is psychologically gratifying for the group because, although they cannot be as successful as the Ewings, they can be more honest.

Machluf introduces an academic or spiritual standard of measuring success, alluding to tradition and to a type of success where "the children of the poor" may outdo the others. Thus, Itzchak and Machluf suggest two ways of using Dallas as a morality play, useful in defining success in ways that provide "substitute frames for self-judgment" (Merton 1946)

17 Acculturation: Machluf's metaphor again refers to a traditional source (cf. note 9 ) by drawing an analogy between the women in the program and Hanukkah candles, which are forbidden for practical use but are there to be admired. Use of this traditional Jewish allusion for defining the pleasures of TV is intended to be funny and serves to contribute to the group's "oppositional" cohesion "versus" the screen. (Hall 1980, Morley 1980).

18 Understanding: This is a rare example of a viewer who may be said not to understand the plot. Trapped in her theory according to which all women are attracted to J.R. Cecile misses the point of the secretary's call, prearranged by J.R. in order to carry out his scheme.

19 In Israel, as elsewhere, much is known about the wellpublicized private lives of the stars.

20 Forum: Watching the bar scene on screen triggers a discussion of the reasons for the prevalence of drinking in Machluf's own milieu. The function of drinking as a means of escape from sordid reality is talked about by the group in the same way they talk about the function for them of Dallas (cf. note 80)
15 CECILE: There's Rebecca, Cliff's mother. Suddenly she's here again.

Yossl: What business are they talking about?

MACHLUF: Oil. These are the actors who were in Israel.

Yossl: Who's the boss, who decides things?

MACHLUF: J.R.

CECILE: Jock

16 ITZCHAK: Look at how money corrupts things, corrupts people.

Cecile: A little money doesn't hurt, a lot does. The money simply pours out in this film.

17 MaCHLUF: I've seen how well poor children do at school and how rich children are just spoiled and fail. [Referring to the women on the program] They're like Hanukkah lights, only there to be seen.

CECILE: My child sees swimming pools on TV and says how good it is to be rich.

Yossl: [Referring to car on screen] What a Mercedes!

18 CECILE: Afton knows what J.R. is asking her to do is not kosher. She said as much to her brother. But, nevertheless, she goes on being with him. They choose beautiful women, one after the other. We see one beautiful girl and after her appears another even more beautiful girl. [On screen: J.R.'s secretary calls to give him an excuse to leave Afton alone with judge.] She is waiting to be next in line [general laughter].

\section{ITZCHAK: J.R. is a bastard.}

ZEHAVA: Would you like to be in his place? I don't think there are many people in the world like him as far as trickery goes. That's why it's not real.

MACHLUF: J.R. is the perfect man. J.R. only loves himself. Couldn't care less about the others.

19 CECILE: In real life Sue Ellen is better than Pam. They say that Pam in real life is not good, she takes drugs.

MACHLUF: [Shakes his head unbelievingly]

Yossl: There is too much cinema here. You know what movies are? Business, money. [On screen: J.R is trying to set up judge with Afton.]

MACHLUF: Filth, that's what we're seeing.

[Discussion while viewing (recording resumed)]

20 MACHLUF: [On screen: Afton sings in a nightclub.] Moroccans are drinkers, what can we do? It causes us to forget about kosher rules, about our tiny flats. Thank God for that. . . . Look at how she sings. 
21 Interaction: Cecile and Massudi make a play on words in Hebrew in saying that "Mitch" is not mitz-the Hebrew word for fruit juice.

22 Forum, Participation: Machluf and Zehava, by association, are reminded of two similar choking instances they have witnessed. Both give parallel, competing dramatic scenarios resembling the one taking place on the screen which does not in the least disturb Cecile, who is absorbed in the program and maintains her own dialog with the screen

23 Forum, Interaction: Yossi uses Dallas as an indirect way of rebuking his wife, who did not follow his instructions. Thus, TV provides shared associations which are activated, as it were, for expressing negative feelings in a subtle way, thus preventing a direct confrontation.

This is only one of the ways in which the program is being used to comment on present problems that occupy viewers in their personal or social lives. Whereas this switch to talking about life deals with sex roles in marriages (cf. note 66 ), the next transition to real life (note 25) deals with the norms of Israeli society in contrast to the presumed norms of Dallas.

24 This is a quote from the biblical Book of Esther associated with the carnivalesque holiday of Purim, which was being celebrated at the time of the interview session.
ZEHAVA: He is simply a good-looking man [J.R.].

[She turns to the others.] We are always talking about good-looking women-talk a bit about men.

CECILE: [Referring to Mitch on screen] Voilà, le plus beau

ZEHAVA: Who?

21 CECILE: Mitch, mitz.

Massudi: Not meetz tapuzim.

CECILE: [Referring to the woman who was choking on screen] Mitch will help her. He studied medicine

22 MACHLUF: Something like that happened to us at work, do you remember?

ZeHAVA: My friend almost died because of this. She swallowed a piece of meat.

MACHLUF: One woman actually fasted two days because there was a wedding reception ...

CECILE: [Referring to Mitch on screen] That's it. They got it out.

MACHLUF: . . . and she came and fell over a tray of turkey meat and put it into her mouth and choked.

Thank God, among the guests there was a doctor, he gave her a stroke on the back, pah, got it all out; very, very hard. And she returned to life.

CECILE: That's it. He's saved her.

ZEHAVA: This girlfriend of mine practically choked to death. They took her in an ambulance to the operating theater and the fear, when she saw everything, made her spit it up all at once. And they took it out; the doctor couldn't believe it. He saw this meat and said: "How could she do such a thing?" A friend of mine told her . . .

MACHLUF: It's a whole cow's tongue she swallowed in one breath.

ZEHAVA: She should eat like a human being. [Asked by her husband to serve tea] Sorry, I'm watching [the program]. Otherwise, afterwards, when they [the interviewers] ask me, what shall I answer?

23 YossI: With us, it's not like with J.R. With J.R. the woman looks after everything. He's got a servant girl. [Zehava and Cecile laugh.]

ZEHAVA: Why, do you mean to say I am your servant?

24 MACHLUF: No, this is your house. You will be given "up to half the kingdom"-it is Purim.

ZEHAVA: [Reacting to coffee, offered to Mitch in film] Coffee, Cecile?

CECILE: [On screen: The doctor examines Pamela.] What a showoff.

MACHLUF: Who's the old man?

CECILE: A doctor. 
25 Forum, Evaluation: By comparing J.R. to an Israeli Member of Parliament who went through a well-publicized divorce case, Machluf is assuming (1) that Dallas reflects American society, (2) that America is corrupt, and (3) that Israel is not. Thus, he again uses Dallas to reinforce his own values.

26 Criticism: In order to support Yossi's argument, Zehava quotes Coca-Cola's frequently broadcast commercial (in Hebrew). She chooses an example par excellence of America inundating the world with its idea of taste - the equivalent of Dallas in the area of material consumptionwhere (1) both represent American (consumer) hegemony, (2) both are relentlessly repetitive, and maybe (3) both add flavor to ordinary life.

27 Participation: In conducting a conversation directly with them, Cecile brings the characters into the livingroom, so to speak, so that she can joke with them, give them advice, and even criticize their actions. In rebuking the doctor, she introduces her own social norms, implying that his invitation to Mitch to come for a meal defines their conversation as something more personal than a business transaction, so that offering money seems in bad taste.

28 Understanding: Massudi, who cannot read the subtitles and claims she does not understand what is going on on the screen (cf. note 1), nevertheless criticizes J.R. for not showing more respect to the court by dressing more formally.

29 Forum: Although the group's discussion overtly deals with what is happening on the screen, they are in effect making use of Dallas to enter into a debate on the role of the sexes. Machluf and Yossi voice the traditional position in this debate, while Cecile brings up the concept of the right of women to self-realization. (This discussion happens to follow closely after Zehava's joking remark about getting an order from "the captain.")
Yossı: I thought they have some private doctor.

CECILE: [In French, offering her diagnosis] Dépression.

MACHLUF: Why?

CECILE: Elle veut un bébé and they ask her to wait too long. She wants it too much.

Yossl: The same story all the time. He [J.R.] feels himself strong with his money. I can tell you, who in Israel could get away with that?

ElıHu: Can I do it?

25 MACHLUF: Akiva Nof, the member of Knesset, had a similar story with his wife. The journalists have shaken the whole country with Akiva Nof until now. In Israel he [J.R.] could not possibly behave in such a way. $\mathrm{He}$ and his money, they would be put in prison. He and his money. They would confiscate it. My opinion is that Dallas is not only a long [full-length] film. Every episode is a film in itself. There's a story. And that's it. Finished

Yossl: But it's a similar story. It's boring. Every week Dallas. Every week Dallas; it has become like advertising. Not Dallas.

ITZCHAK: But each time it's a different story.

26 Zehava: "The taste of life."

27 CECILE: [On screen: Mitch is having breakfast with a plastic surgeon and his wife whom he saved from choking.] But [please] without the bones.

CECILE: [The plastic surgeon offers to pay Mitch.] You both invite him and also give him $\$ 5,000$ ?

ZFHAVA: A good offer.

CECILE: Great, the future is now Mitch's.

28 MAssudi: (Change of scene: J.R. comes to the court.) He came without a jacket.

ZEHAVA: [Asked again to bring some tea] Well, I got an order from the captain so I have to bring it.

CECILE: [On screen: J.R. insults Pamela at breakfast table] Now, there's violence.

29 MACHLUF: Why does Pam go to work? Her husband is so rich.

CECILE: But they have no satisfaction in life. So they search

Yossı: Satisfaction in life.

CECILE: What does it mean, why does she go to work? What will she do? Wait until Bobby comes home?

Yossl: Does she lack anything? Of course she does not have to wait that much for her salary. She couldn't care less. I stand in queue in the bank on the first of the month. 
30 Criticism: Cecile's relief upon hearing the formal defini tion of family relationship is a sign of her awareness that Dallas scripts hover on the borderline of kinship taboos, which the characters constantly threaten to-and sometimes do-break (cf. note 64). Cecile intuitively senses that this policy of brinkmanship is caused by (1) the need to produce new entanglements within the rather closed Dallas circle (a new relative has to provide a new twist in the plot) and (2) the need to provide new excitement to viewers who due to the socializing influences of television, become more and more immunized against shock.

31 Yossi's observation (prompted by seeing Cathy's striking blue eyes) is interesting mainly because it is definitely not true of Dallas characters in general and thus can only express what must be his image of what WASPs look like.

32 Acculturation: It is not clear whether Zehava considers the Dallas custody trial real or not when she compares it to the Beit Din, which deals with cases of marriage and divorce in Israel.

33 Participation, Gratification: The same norm that is behind participants' embarrassment over public discussions of sex (see discussion of Dusty "not [being] a man," below) may also underlie Cecile's reluctance to see Dusty's impotence made public in the show. Another, less conscious, reason might be that one of the sources of enjoyment of the series is the viewers' "privileged" position over that of other characters in the show in knowing secrets. Thus, the disclosure of Dusty's secret "deprives" Cecile, the avid viewer, of a position of power.

34 Interaction: Cecile's tactful way of describing Dusty's impotence is indicative of the way group members tend to use euphemisms and literary or biblical expressions-or may even leave sentences unfinished - when sex is being discussed

35 Interpretation: The discussion provides a running commentary on what is happening on the TV screen, beginning with definitions of the conflict (Cecile sees it from Sue Ellen's point of view - money versus heart; Itzchak sees it from the court's point of view-sex versus love), moving on to predictions about the outcome of the trial and speculation about Sue Ellen's motives. Note that the implicit question in Machluf's statement that Dusty is "not a man" is understood by Cecile to mean, "Why should Sue Ellen want to stay with Dusty?" and is answered accordingly. For her, not having sex is proof of true love.

\section{CECILE: TOO much money.}

Yossl: [On screen: Another glamorous woman appears in a car.] She doesn't work. [Everybody laughs.]

30 CECILE: [Cliff is introduced to his new sister.] Suddenly he discovers a half-sister. It's lucky that she said to him she's a sister, otherwise, he could have fallen in love with her.

31 Yossl: They all have blue eyes.

CECILE: Now, please [quiet]. That's the trial for the child.

ZEHAVA AND YOSSI: Moroccans want only food.

Yossl: Not Dallas.

CECILE: [Responding to the general noise.] You've no heart, this is a trial about the child.

32 Zehava: [If] it was a Beit Din [rabbinical court] this would be a trial. Of course the child will go back to his mother.

Yossl: Is this Sue Ellen's lawyer?

ZEHAVA: [When Gil gestures her to stay in her seat rather than get the tea] I get up_immediately he looks at me. [To the interviewer] Don't worry. You will ask me, I will answer you.

33 CECILE: [On screen: Sue Ellen's lawyer discloses he has doctor's certificate about Dusty.] Oh, what they're going to discover now. It's not nice, in public like that.

GIL: What is not nice?

CECILE: What they're going to discover.

GIL: Do you know what they'll discover?

CECILE: I knOW.

GIL: How do you know?

34 CECILE: For some time he's not been a man.

GIL: From former episodes?

ZeHAVA: Yes.

CECILE: Since the accident.

35 ZEHAVA: And he told her beforehand: "It's a pity for you to go on with me, I don't want to go on." And it was because of her. He was in the airplane because of her.

CECILE: [Sue Ellen's lawyer calls her "the girl he (Dusty) intends to marry - his future wife."] "His future wife." Here, at least, there's a nice contrast. The second family she's falling into-people... not just

people with heart, people-not just money.

ITZCHAK: Just for that, she will get the child now. CECILE: Yes, sure. It's people ... not just the money. MACHLUF: After the accident he is not a man any more. 
36 Forum: Cecile introduces here a new concept of distributive justice: equal allocation of babies. The basic facts of the story - that J.R. has had a baby with his wife's sister and later buys the baby from her-serve only as the basis for an argument over whether J.R. has a right to another baby. The total destruction of the institution of the family passes by, unnoticed and uncriticized.

37 Criticism: Machluf calls attention to the improbability of some of the dynamics of family relations in Dallas. How can babies be bought, sold, and transferred? In their answers, Cecile and Zehava avoid the issue of how J.R. can accept the fact that the baby has another father.

38 Acculturation: The award is immediately translated into Israeli currency, and Zehava remarks that with the rate of inflation in Israel, this amount of money will increase considerably within a short amount of time
CECILE: But she wants to be with him. Also he had the accident because of her.

ITZCHAK: So they shouldn't think as if she wanted... MACHLUF: (To lawyer on screen) Because of lovethat's right.

CECILE: J.R.'s lawyer is not pleased.

ZEHAVA: (Repeating lawyer's words) "True love."

36 CECILE: [On screen: Sue Ellen's lawyer says: "How can we deprive her of the only child she'll ever have?"] J.R. already has Kristen's son. It's enough. ITZCHAK: [Sue Ellen's lawyer wins.] She beat him. CECILE: He [J.R.] killed her [Kristen] and the child remains.

Yossl: But the judge is corrupt. He talked to J.R. in the cafe. He is corrupt.

ITZCHAK: They didn't show a bribe.

CECILE: In the former... she was pregnant and she came to get money out of him . . . to blackmail [J.R.]

if not she would tell her sister the truth.

Yossl: The judge ... he talked to him in the cafe ... he's corrupt.

MACHLUF: It looks like the end.

CECIIE: And Cliff came in at that moment and accused him of murder.

37 MACHLUF: I don't understand one thing. J.R. knows, he heard from his wife that the child [John Ross] is not his and in spite of that he wants to take him.

CECILE: But it's his name. His ... how do you say his nom propre, his name in the world.

ZEHAVA: That's right.

CECILE: His name. It's the principle. It's his wife. It has to be his son. If not his whole name collapses, his whole honor in the world rises and falls with this.

MASSUDI: I never see it [the program].

38 MACHLUF: [Judge's decision about the money Sue Ellen gets for maintenance is announced.] \$5,000 a month times 360 .

ZeHAVA: It will increase. Until then it's linked.

CECILE: [Anticipating the announcement on screen] It was given to his mother. [On screen: ... "to Sue Ellen Ewing ...."] Marvellous.

ZeHAVA: I knew.

Yossl: $\$ 1,000$ a month [for the baby].

CECILE: Oh, no. [J.R.'s smile at the end of the show.] What a marvelous look.

ZeHAVA: Finished. Now the examination [the interview session]. 
39 Acculturation: Machluf alludes to his earlier joke about Hanukkah candles (cf. note 17). Just as with the Dallas women, the amounts of money that are paraded on the show are only to be admired from a distance.

40 Methodology: To a large extent, this is true, as most of the questions that were supposed to be brought up in the focus discussion were already touched on before the formal discussion took place. These questions focused on characters' kinship relations and their personalities as well as on how realistic they are as people, the extent to which Dallas reflects America, the concern with babies, and the gratifications of watching Dallas.

41 Methodology: having the participants recount the story of the Dallas episode was intended to reveal: (1) the extent to which people in various cultures, who depend on subtitles or less, understand the basic plot; (2) the extent to which this understanding is shared or universal and the points at which it varies; and (3) differences in styles of narration that reflect variations in what may be called "critical distance" from the story as well as various traditions in storytelling.

42 Interaction: Zehava demurs, passing the task on to someone else, thus betraying a slightly awkward feeling now that the group has entered into organized discussion. They soon forget about this.

43 Interpretation: By "the law of Texas," Yossi means the law of the "jungle" where those with power do as they please (cf. Yossi's comments at note 46).

44 Narration: Dallas is almost impossible to relate in a story form because it is actually a succession of segmented subplots. One way of recounting what goes on is by pointing out a main theme-which is what Machluf does.
GIL: So she got $\$ 1,000$ for the child as well?

CECILE: It's nothing to him ...

ZEHAVA: It's nothing to him ...

ITZCHAK: $\$ 5,000$ maintenance and $\$ 1,000$ for clothes.

ADI: $\$ 5,000$ goes straight into the fuel for the car.

ITZCHAK: Nonsense, what is $\$ 1,000$ ? It's like 1,000 lirot here [comparing it to Israeli money].

MACHLUF: $\$ 6,000$ times 360 lirot.

ZEHAVA: He talks in millions, not in thousands.

ITZCHAK: [Repeats] There a thousand dollars is 1,000 lirot here.

ZeHAVA: It's nothing. Nothing.

39 MACHLUF: That's what we're condemned to. "We can but admire them."

[Program ends, discussion begins]

40 CECILE: [To interviewer] I think you got your answers within this-while we were watching the movie, right?

GIL: Let's start so we can all get some sleep.

ZEHAVA: If not you can [all] sleep here tonight, with the snow we've got here.

ELIHU: It's actually snowing?

ZeHAVA: Yes, wet snow.

41 ADI: I'm going to ask you something simple. I want each of you to tell me what was in the film. As if I hadn't seen it or as if you were coming to tell me tomorrow morning. ... Can somebody please tell me what happened in the film?

Yossl: The same as last week [everybody laughs]. Believe me, the same faces. Only the judge is new [laughter].

42 Zehava: Suzi [Cecile] always sounds as if she can explain things.

43 Yossi: In Dallas there's the law of Texas [laughter]. ADI: What's going on here? Tell me what happened in the film we've just seen.

44 MACHLUF: To the point. The main thing in the movie was the trial, who'll get the child. Who'll get the child. This family, it has a lot of surprises.

ZEHAVA: [Serving chicken] Have a taste. This is a surprise really. 
45 Narration: Machluf goes on to tell the story of that theme in terms of one linear plot. It is useful to look at his version in light of Propp's scheme for analyzing folk tales, according to which the basic narrative unit is called a "function"an act of a character defined from the point of view of its significance to the course of the action (Berger 1981). Since each episode of Dallas is a segment of a larger story, the Proppian analysis is, necessarily, incomplete, but it gives one a good picture of the roles attributed to the different characters.

In Machluf's version of the kidnapping attempt, Miss Ellie is described as the "hero," "owing to his mother being honest. ..." She fights the "villain," J.R., "wanting to kidnap his child" ("struggle") in order to repair the harm caused to a member of the family ("villainy") because she understands what "a baby means to his mother." She returns the child to Sue Ellen, thereby repairing the harm caused to a "family member" ("liquidation"). Thus, the "princess" gets what "she lacked and wanted" when "the child went back to his mother and she also received alimony."

It should be noted that, due to Dallas being different from the classical folk tale (1) in its cyclical, unending nature and (2) in J.R.'s alternating functions as villain and hero, Sue Ellen's future wedding - which completes this sequence-is actually a remarriage to the villain-turned-hero.

46 Evaluation, Narration: Unlike Machluf's account, Yossi's is paradigmatic rather than sequential. The story theme, according to Yossi, involves the carrying out of "dry law" - or unjust law-which contradicts justice. By judging the story in this way, he is in fact defining his own notion of justice: that law should consider intentions and actions and not their accidental outcomes.

The suspicion that beliefs or values precede the logic of the argument-i.e., that Yossi's definition of justice is derived from his disapproval of Sue Ellen's and Dusty's romance - is supported when he joins Machluf in using opposite logic in arguing the justice of another case (cf. conversation at note 66).

47 Narration: Cecile tells the story as two interconnected subplots in which, according to Proppian terminology, J.R is the "villain." She describes him in the first subplot-as does Machluf-as acting in contradiction to his mother and in the second as a new cause of Pam's misfortune.

In terms of Proppian theory, Cecile describes Pam as "lacking and wanting" - "She wants to adopt a child and they won't give it to her." The functions Cecile elaborates on in her narrative about Pam are: (1) "trickery," where the "villain" (J.R.) uses information he receives ("delivery") about his "victim" wanting a baby to try to trick her into changing her course of action-"He hurts her [by telling her] that it's because of his son that she wants a child"; and (2) "complicity"-J.R. influences her "so much that Pam thinks he's right," i.e., "The victim submits to deception."
45 MACHLUF: Last week the whole episode was based on J.R. wanting to kidnap his child. He came with a helicopter and tried to make use of his mother for kidnapping the son and owing to his mother being honest and she understood what might happen to her, and understood as a mother what a child and a baby means for his mother, she didn't want to follow him and she returned the son to Sue Ellen. Here in this movie, I think the main thing is that J.R. wanted to get back his son at any cost and in the end the court decided what it decided and we saw at the end that the child went back to his mother and she also received alimony for her and the child.

ADI: Anybody else want to tell what was in the film?

46 Yossl: I will tell you. The law, the trial, you saw today in the film, it's called dry law. Why is it dry law? It's law that doesn't have any law, does not have a sujet, how do you call it?

\section{CECILE: Sue Ellen.}

Yossi: Not Sue Ellen. The basis of the law, the subject. This law is dry like. ... I don't know how to describe this. Who says that the court should have to decide that the child should stay with the woman? Whose fault is it that he had an accident? Was it J.R.?

CECILE: [Correcting] No, her friend.

Yossl: His friend.

MACHLUF: No, her friend.

Yossı: Yes, her boyfriend, and he can't go to bed or make children with her, or something. Whose fault is it? She shouldn't have betrayed him, and the court should not have cleared her so that she can get the child.

ADI: But other things happened. Tell me as if I hadn't been here.

CECILE: Just a moment. Do you want us to tell the story or to analyze?

ADI: Tell us what happened as if I didn't know.

47 CECILE: Here the film starts after J.R. wanted to kidnap the child and the mother did not agree to it. His mother, of course. Actually, that's what we saw in the beginning of the movie. It's also about Bobby and Pamela who passed through a difficult period that she wants a child as if she's in a depression ... .

\section{MACHLUF: A child at any price.}

CECILE: She wants to adopt a child and they won't give it to her in the near future; and she's passing through a very difficult period; and J.R. tells her openly, he hurts her, that it's because of his son that she wants this and I think that J.R. on every subject is trying to influence people with his opinion so much that Pam thinks he's right. 
48 Narration: Following the segmented editing of the series itself, Machluf mentions a broader range of subplots according to the characters involved: (1) J.R. and the baby; (2) Pam and the child; and (3) Pam's brother and his mother. It seems that some events, which created a lot of excitement while the participants were viewing the show, were forgotten when they recounted it later-as did the incident where Mitch saves the doctor's wife from choking (cf. conversations at notes $22,26,27$ ) - perhaps because this scene is complete in itself and therefore does not remain unresolved and troublesome in the viewers' minds in terms of the ongoing story.

49 Criticism: The choice of the child who has barely appeared on the screen indicates that "central character" was understood by the participants in terms of the character's dramatic function in the plot and not in terms of his or her actual (speaking) role or length of appearance in the show.

50 Criticism, Identification, Evaluation: Two surprises emerge from the group's choice of central characters: (1) all three of them are women, of whom two are victims; and (2) although it is stated right at the beginning that "everyone" is attracted to J.R. (see Itzchak's comment at note 7 and the conversation at note 8), he is not made one of the central figures. This indicates that the choice of main characters is based on a moral criterion, that is, the group chooses characters they can approve of and identify with. According to Herzog-Massing (1984) who interviewed German viewers, identifying with characters who represent the superego (e.g., Miss Ellie) legitimizes the viewer's pleasure in watching the character who acts the id-J.R. Our group's choice probably has a similar meaning.

51 Interpretation, Evaluation: Machluf defines Sue Ellen as the type of character who "commutes" between the extremes of very good and very bad characters (cf. note 14). Thus, from being under the influence of the villain (cf. note 45) who makes her into a promiscuous alcoholic, Sue Ellen has moved - through her contact with a child and an impotent lover-to being a nurturing mother and nurse.
AdI: We'll soon get to J.R. Itzchak, you want to tell us a little?

Yossl: He [Itzchak] was a lawyer in Morocco. Before he talks, tell me which party's J.R., Likud or Ma'arach? [everybody laughs].

ITZCHAK: So he [J.R.] tried to bribe the judge and didn't manage and he was also sure that in the court he would use all of her [Sue Ellen's] past in order to win and to get the child legally into a proper family and this also didn't succeed. And very simply, the court did not have a choice because her lawyer actually proved that she's actually a decent woman and that she didn't come [to Dusty] because of lust and because of

MACHLUF: ... pleasure.

ITZCHAK: Because of her own interests. She, after all, came to look after an invalid and to bring up her child in a family of a ...

CECILE: .... decent sort.

48 MACHLUF: There are some points in the film, which she hasn't told. There are several points. Here it is not only about J.R. and about the child; it's about Pam, it's about her brother, how he succeeded with his mother. It's about Pam. In my opinion Pam loves the child [Sue Ellen's]. Why does she love the child?

ADI: Who do you think is the most important character today [in today's episode]?

CECILE: The trial.

49 ZFHAVA: The child, the child.

ADI: No, the most important among the actors.

50 CECILE: Sue Ellen.

ZEHAVA: Yes.

51 MACHLUF: I agree with her. In the trial today we discovered that Sue Ellen went with her boyfriend, begging your pardons, without the sexual contact, that's what the judge says. Sue Ellen, in her role at the beginning of the films, in all the episodes, she always went after alcohol, after men-wanted to revenge herself against her husband. Her husband also always went with women, she also says, "I'll also go."

ZEHAVA: She wanted to compete with him.

MACHLUF: But today we say something special that we knew from the lawyer: that she went faithfully and that she went, like Cecile says, to look after an invalid and her own child.

AdI: Who's Sue Ellen, what are her connections? I haven't seen [the program] before.

CECILE: She's J.R.'s wife and was unfaithful in the beginning with Cliff, with Pam's brother. 
52 Interpretation, Interaction, Participation, Mutual Aid: Following Machluf's statement regarding the birth of Sue Ellen's baby, a debate ensues about how to interpret the information relating to the identity of Sue Ellen's baby's father (note 11). Whereas Machluf believes what Sue Ellen says Cecile does not and argues that neither the viewers nor Sue Ellen possess enough information to know the truth of his identity.

Cecile talks about Sue Ellen as if she were a real person. Therefore, although her analysis is very persuasive, it ex cludes a more analytic or "distanced" kind of argument which might state that the program's writers themselves have not decided - or prefer to leave open-the identity of the baby's father, as such ambiguity might be useful in creating other twists in the Dallas plot.

Analyzing characters' motives from their own point of view, or from the point of view of other characters, rather than using the critical or "poetic" code (which would mean looking at the demands of the plot and the genre), is typical of this discussion. The group's way of relating to characters as if they were real often leads them to speculate on "the moral of the story" or to discuss life in general or their own lives.

53 Forum: Sometimes it seems that character analysis is used as a means for viewers to bring up their own problems. In the following, Zehava, who is overtly discussing Sue Ellen's mótives, evokes a popular truism about urhappy wives "taking it out" on their children. Since at this point Sue Ellen is definitely not "taking it out" on her children, Zehava's interpretation suggests that she is making use of Sue Ellen's predicament to voice her own unrevealed problems or to air guilty feelings that are easy to express while discussing Dallas

54 Interpretation, Forum: This very romantic image of Sue Ellen is described consistently by the group, which attributes those aspects of her behavior considered dubious to external forces ("ambitious mother") and her so-called positive actions to her "real will" ("she understood," "she came to the conclusion"). Thus, the participants cast her in a far more stereotyped role than is played by her on the screen. (See the reactions to Machluf's meek response attempting to cast doubt on Sue Ellen's disdain for material things.) It is possible that the group's normative approach makes it vital for the participants to idealize Sue Ellen in order to allow themselves to empathize with her. The way in which they do this is demonstrated in the following note.
52 MACHLUF: And from this the child was born.

CECILE: From this they say that this is the child. And afterwards there was an examination in the laboratory and we saw that J.R. bribed the doctor so we as spectators don't know exactly who the father is. Even if the result of the lab really says that it is Cliff's son, because we saw J.R. bribing the doctor in the lab, so we don't know

MACHLUF: But Sue Ellen said to J.R. explicitly that it's not his son.

CECILE: She said but

MACHLUF: . . . in the presence of his father.

CECILE: She actually could not know because at that time she went to bed both with her husband and with Cliff.

ADI: Do you all agree Sue Ellen is the main character today?

ITZCHAK: Sue Ellen.

Yossl: The main character, that is.

ZEHAVA: It was all based on her. Because the child belongs to her

ADI: What causes her to behave this way?

53 ZEHAVA: Because of the troubles her husband caused her. And her revenge ... where does she take it out?

Yossı: The jealousy she has against her husband

MACHLUF: It's not jealousy.

Yossl: Jealousy and the principle of it.

ZEHAVA: It's natural that when the husband and wife quarrel, where does all the tension go? Onto the children. The wife hasn't got anybody to unload it on. On the neighbor? No, she can't. On the children.

54 ITZCHAK: I think that actually she understood that she made a mistake when she married J.R. at all and she came to the conclusion that the life she has lived with him until today was not a clean life. And she didn't find the love, the honesty, the normal life. All in all, according to what we understood from other scenes, she has an ambitious mother who pushed her onto J.R., to marry him because of the money, because of the economic situation and today she has already understood she's happier with her boyfriend ...

MACHLUF: Don't forget, Itzchak, that he's also very rich.

ITZCHAK: Not because of the money. 
55 Attribution, Evaluation: In the debate over Sue Ellen's motives, Zehava, Itzchak. Machluf, and Cecile reinforce each other in interpreting what Sue Ellen "learned" from former episodes.

(1) Money does not equal happiness; (2) normal family life equals happiness; therefore (3) Sue Ellen is looking for normal family life. In the struggle between viewers' moral repudiation of Dallas's worldly success and the notion that it is what "everyone" dreams of (see discussion at note 8), this one-sided, simplified description of Sue Ellen serves to strengthen the moral rejectionist or "oppositional" position. Describing Sue Ellen-who herself is rich and glamorousas a character who rejects wealth, power, and prominence for the old-fashioned values of home and family makes it easier for the more disadvantaged viewers to do the same.

Sue Ellen's move from the ranch of one oil-dynasty family to another is, therefore, interpreted as a radical ideological change. Thus, the group makes her out to be an example that provides them with a substitute framework for self-judgment (Merton 1946). Through her, material standards for success can more easily be superseded by moral standards. Through Sue Ellen, who has it all but rejects wealth, viewers who do not have it can reject the notion that economic success is the only criterion for self-judgment. Note that this "pedagogic" interpretation of Sue Ellen's behavior is not the only one possible. Indeed, viewers in other groups (some of the American groups, for example) are aware that Sue Ellen's present mood, true to the genre, is bound to be reversed at any moment.

The discussion treats Sue Ellen's current state as the happy end of a classical "closed" narrative. This may be due to lesser experience with TV serials, or it may be ex plained functionally, in the sense that Sue Ellen is being used as an anchor for the rejection of the values of the program

Critical theorists may well argue that such rejection of what is perceived to be the manifest message of the program may imply acceptance of its intended (latent) message! According to this position, viewers will be misled into false justification of their own social status by comparing themselves to the unhappy lot of the Dallas characters. These viewers would then be considered to have been no less "hegemonically" influenced than viewers who chose to emulate the affluence of Dallas. Thus, both the "dominant" and (ostensibly) "oppositionist" readings (Morley 1980) manipulate the viewer. If both readings may, indeed, be considered hegemonic then Newcomb and Hirsch (1984) are correct in saying that the concept "is so wide as to keep everything out or allow everything in." In other words, the concept may not be useful in explaining "differences" in reading. For a similar analysis of these two related themes in prime-time television fiction generally, see Thomas and Callahan (1982), who conclude that the message is, "Just in case you don't make it, don't worry. It's not so great at the top."

\section{ZEHAVA: She was looking for love.}

ITZCHAK: She already learned one thing from former episodes, that it is not the money that makes her happy and she came to the conclusion ...

MACHLUF: [In French] L'argent ne fait pas le bonheur.

ITZCHAK: That she doesn't care that much about the money as to live a regular and normal family life

CECILE: To live in a quiet, normal atmosphere.

MACHLUF: You touched a point about which I wanted to speak.

ITZCHAK: She so much doesn't care today about her husband and the richness and the money. The main thing is to be happy and that she live a normal life, she and her son. She found it all with her new boyfriend.

CECILE: Of course, she has already come to the conclusion - not money, not parties, not this or that, but to live a quiet, normal family life.

\section{Yossl: A happy life.}

CECILE: Faithful husband, clean atmosphere, the child, the grandfather. Now she feels satisfaction out of something. She used to look for ways for, how do you say, for escaping from it by drinking ... . here she isn't looking for anything [anymore]

Yossı: If she has been considerate about J.R., that joker, until now, it's because of his mother.

ZEHAVA: She [Miss Ellie] was good.

Yossı: She was considerate of his mother. It's a fact that in the last episode ... it's the second time l've seen Dallas and the first time was last week. Because of his mother, he did not kidnap the daughter.

\section{MACHLUF: It's a son. He's a male. He's been} circumcised.

YossI: And because of his mother, he didn't kidnap that is, she [the mother] returned it.

ADI: Is there another way to hurt J.R. apart from the son?

Yossi: Never, she can't hurt him because of the backing he's got in the law, and his money and the bribe.

\section{CECILE: Only the child.}

Yossl: The child is the one who might suffer.

ADI: Do you like her [Sue Ellen]?

CECILE: As a person, yes.

MACHLUF: As a mother. 
56 Narration: In describing Sue Ellen's past, Cecile acquires the rhetorical flair of a storyteller and uses parallel, contrasting phrases that emphasize the conflict in their meanings. This accentuates the paradox of Sue Ellen's state - where she had everything but had nothing, she was rich but she was poor-and strengthens the group's stereotypical concept of Sue Ellen, which is much more one-sided than what is presented on the screen (cf. note 54).

57 Interpretation, Gratification: The choice of Pam as the second central character is an indication that she provides similar gratifications to those provided by Sue Ellen, who is seen by this group as a spiritual saint. Assuming that the prevailing role models for women in American culture are those of homemaker/wife, career woman, or glamour girl, Pam clearly represents the last, whereas the image of mother is usually related to those qualities that suggest virtuousness and lack of glamour.

In seeing Pam, who is glamorous and rich, as an unhappy woman who longs for a child, the women in the group, who are occasionally cramped by their roles as housewives and mothers as well as by their husbands (who support this role), are reassured of their own status. Thus, they are strengthened in their belief that their own lives are more rewarding than those of rich and glamorous women like Pam. Her wealth and glamour are no compensation for what is every woman's "natural" desire for children. She would like nothing better than to be a mother hence she is to be pitied and not envied.

The extent to which discussion group members adhere to Pam's pious image is striking particularly in light of evidence which suggests that viewers tend to regard a character as less two-dimensional by supplementing his or her image on screen with information about the actor's real life. Thus, Herzog-Massing's (1984) survey of German viewers suggests that J.R. is seen as less evil and Pam as far less loving by virtue of such extramural knowledge. The present line cannot be dismissed as caused simply by ignorance about the stars' lives, as the group expresses considerable knowledge about what happens behind the scene (cf. note 68).
56 Ceclle: Today, as a mother, as a person, yes. Because she had no life. Then she had everything and she didn't have anything. She had a husband and she did not have a husband. She had money and she could not enjoy it without a husband. She had a child at home and she did not love it, and the maid looked after it. She had everything and nothing worked. She went drinking, she tried everything. Today she doesn't drink anymore, she looks after her son. And she does not want to cause harm to the family because after all they did not do her any harm apart from her husband. It hurts her that the grandmother cannot enjoy the child, but she has no other choice.

ADI: Who is the second most important person in the film?

MACHIUF: But one can still talk a lot about Sue Ellen.

ADI: But it can take all night. Who's second?

57 MaCHLUF: Pam, too, she is the second person. She so much wants a child, at any price, and she can have a child, but she is afraid of this hereditary illness of the father.

CECILE: But I think you're making a mistake.

MACHLUF: It's this illness that she fears.

ADI: Which illness? I didn't see that film.

MACHLUF: Yes, in the earlier films. That was an illness from which a baby cannot live more than a year or two. Something like that, if I remember. 
58 Interpretation, Participation, Mutual Aid: The fact that Cecile updates Machluf on Pam's situation demonstrates the participants' willingness to "play the game" that Pam is real. This kind of involvement can be explained by: (1) the nature of TV series, which, unlike films for instance, occur regularly and independently of whether people view them or not, thus creating an illusion of another, real world that carries on on its own (Booth 1982); (2) the ongoing story of TV serials like Dallas that never end and therefore occupy viewers' minds between episodes, while TV series that are composed of (episodes of) complete stories are forgotten once they are over; and (3) the slow pace of serials, where the same unsolvable problems are dragged out endlessly, with slight variations, which give them a lifelike quality.

Thus, arguments about the facts of the story can arise easily even between regular viewers - because of the abundance of detail, the ambiguity of the plot due to the writers keeping it as "open" as possible to create different options, and the different importance each viewer attributes to various details according to how relevant they seem to him or her.
59 Narration: Analysis of characters often turns into telling the story. In Proppian terms. Pam as dramatis persona here is the "princess" who "lacks" what she most wants. In Itzchak's words: "She did go through a depression." She goes to a "donor" who suggests providing her with a "magical agent": "The doctor ... he suggested to her that it's not his specialty, the general practitioner's, that she can go to a psychiatrist who can help her." Here the plot comes to a halt because Pam refuses for the time being to take the next step.

60 Forum: After mistakenly saying that Pam has a drinking problem, Zehava goes on to discuss what appears to be her husband Yossi's drinking problem. This demonstrates how the process of negotiating the meaning of what goes on on screen works both ways: Just as problems on the TV screen can provide a stimulus for a viewer to articulate his or her own problems, so interpreting what goes on is affected by those issues occupying the viewer's mind.
58 CECILE: But I think that you're making a mistake because you didn't see one chapter

Machluf: Possibly, possibly.

CECILE: They've already come to the conclusion that she can have healthy children. There is no fear of that. By now she can have...

MACHLUF: Nevertheless, she always doubts ...

CECILE: ... once she did not want to have one because they told her such and such and such. But later they found out it was not true. Any child can be healthy but the problem now is ...

ITCHAK: On the whole, Pam ... her story . .

MACHLUF: . . . is more painful than anybody's. She wants a child at any cost.

ITZCHAK: Her story

ZEHAVA: God bless her.

MACHLUF: Wants to adopt it. And even in that she has no luck. Even in adoption she has no luck. She has to wait

CECILE: Let's put it this way. I think that apart from the main story in this whole J.R. film the problem of Pam with her husband is more [important] than anything. And this, I think, is the second character in this ... [general noise].

ITZCHAK: This is the second character in the whole film. The most popular one. It's her story. She and her husband and all the problems she goes through-in order to adopt a child and in order to give birth to a child. And she objects, she very simply objects-as we have seen in the last episode-to go to a psychiatrist, Pam.

ADI: Why? Why does she object?

59 ITZCHAK: The doctor, the doctor ... She did go through-here in this sequence-go through a depression, and he suggested to her that it's not his specialty, the general practitioner's, that she can go to a psychiatrist who can help her, who can help her ... in this and she objects, quite simply she objects.

ADI: Why do you think she objects to going to a psychiatrist?

ZEHAVA: So that he won't discover, perhaps ...

Yossi: Her illness.

60 ZEHAVA: Her illness, her drinking.

MACHLUF: No, with Bobby she does not drink. We're talking about Pamela

MACHLUF: Bobby's wife.

ZEHAVA: I just now . . I l just now thought about the glass you [Yossi] were drinking [general laughter].

Yossı: The glass I was drinking? 
61 Interpretation, Gratification: Differences in meaning emerge clearly when the psychiatrist's "function" in Itzchak's version is compared to his "function" according to Cecile. Here his role tends to be one of a "villain" rather than of a "magical agent." The psychiatrist may "trick" Pam by undermining her own will and convincing her to "comply" with him and abandon her goal: "He'll ... tell her [will advise her against having a child] and she wants it so." At this point both narratives are legitimate. Only in retrospect will it be possible to define the psychiatrist's "function" in the story. But meanwhile, the pleasure participants derive from watching the weekly Dallas installments comes from the ability to interpret the story according to their inclinations and thereby to forecast various sequels to the plot.

\section{Zehava: When you said "One glass I had-'}

Yossi: Am I known to count?

ZEHAVA: I said to myself: "How many glasses did he have?"

MACHLUF: He drinks, she went crazy [everybody laughs].

YossI: It's finished and I still don't feel anything.

ZEHAVA: Ah, he still didn't feel anything ...

MACHLUF: It doesn't matter

ADI: Why does she not want to go to a psychiatrist? Why ... not?

CECILE: [Assisting Adi] What prevents her?

MACHLUF: I think she's afraid of the illness-that she'll bring a baby into the world-and she can bring a baby-and later he will die.

ZEHAVA: If everybody were to think so they'll never have babies.

ITZCHAK: I think that she is simply afraid to go to the psychiatrist, maybe because of what Sue Ellen went through, when she was

MACHLUF: ... was in treatment with a psychiatrist.

ITZCHAK: Was in treatment-maybe it can affect her-and also she believes in her incapacity to bring a child and that surely stops her, prevents her from going to a psychiatrist. That's my opinion.

61 CECILE: Maybe the psychiatrist will discover some defect in her or something and will tell her she is not able to look after a child and she wants it so much.

ADI: When Bobby told her to go to a psychiatrist, what did she tell him?

ITZCHAK: No psychiatrist.

CECILE: She did not agree. She did not agree. Maybe he'll discover something in her which will be against ... [having a child] and she wants it so. Maybe she wants to escape from the truth? Maybe the psychiatrist will discover something in her

MACHLUF: There's a difference between Sue Ellen and Pam.

ADI: Let's leave Pam now and tell me... 
62 Evaluation, Mutual Aid: Group members blame Pam - to different degrees_for her "slip," though all of them regard her as a victim. Cecile sticks to the definition of Pam as a good "polar type" character (cf. note 14), absolving her of all blame in the seduction attempt- "She didn't try [to be unfaithful] . . . it came by itself." Cecile seems to identify most with Pam in ascribing the incident to external factors, thus excusing Pam in the same way in which she would excuse herself. Machluf describes Pam as a shifty or

"changeable type": "Once she tried to be unfaithful" - thus blaming the event on her own will, while Yossi remains undecided: "She was persuaded."

Analyzing this sequence in terms of narrative building, the context should be kept in mind. Up until now Pam was described as the "princess" who "lacks" what she most desires. Therefore she is easy prey for an interested "villain"i.e., potential lover - who gathers information about her trouble ("reconnaisance"), and receives it ("delivery"). Within this context, Machluf and Cecile describe the seduction at tempt as: (1) "trickery" - "Pam is not a drunk and not an adulteress," "it came by itself"; (2) "complicity" - "It wasn't intended but it came; and [the adulterer] had to be caught" (3) "victory," where the "villain" is defeated by the "hero"and one telephone call ... a ring from Bobby saved the whole situation.

It is easy to see how the same pattern of plot can occur while different characters play the role of villain. Both J.R and the psychiatrist were described as deceiving Pam into not wanting a baby (notes 47,59 ) thus making her more desperate so that the potential lover could seduce her and make her betray her husband.

63 Narration, Attribution: Whereas Sue Ellen and Pam are both victims - Sue Ellen of her circumstances and Pam of her genetics - and participants sympathize with their misfortunes or their "lacks" rather than with any positive attribute (their main attribute, glamour, is never mentioned), Miss Ellie's quality of being "the most logical and honest in the whole family" puts her among the Ewing men — not just as an equal, but as the most virtuous. In relating the sequence of the story described here, group members deal with the problem of J.R. playing alternating roles as victim and hero. In Itzchak's view, Miss Ellie acts as the "father of the princess" who discovered that the person he thought was a hero was, in fact, a "false hero" who "presented unfounded claims," and the false hero is "exposed." "In the last sequence, she really discovered ... . that he's not honest" and so on. But unlike folk tales, Dallas is an unending sequence of plots where nothing is irrevocable and options always stay open. Therefore, the last kidnapping episode having ended, Miss Ellie goes on to propose a "difficult task" to the "hero" - who happens to be none other than the unmasked false hero. His task is a corrective version of his evil act: "She told her son: "If you want to bring back the child-only with his mother' "- he has to bring back the princess with the baby. And like all fairy tales, this sequence will end within a few more episodes in a wedding, although being the cyclical, never-ending Dallas, it will be J.R. and Sue
62 MACHLUF: No, just a moment. I'll say what I have. . the difference between Sue Ellen and Pam. Sue Ellen was a drunk, was an adulteress. Two things, very huge ones. Pam, according to the movie we saw, is not a drunk and is not an adulteress. Once she tried to be unfaithful and one telephone call was sufficient to prevent it

CECILE: She didn't try.

Yossi: She was persuaded

CECILE: No, it came by itself. She didn't try. It wasn't intended. It wasn't intended.

MACHLUF: It wasn't intended but it came; and it had to be caught. The adultery had to be caught and a ring from Bobby saved the whole situation.

ADI: Now, we left the two women, Pam and Sue Ellen. Who is the third person - and this is the last one we'll discuss - the third most important.

ITZCHAK: It's the mother [common agreement in the group]

ZEHAVA: It's the mother really.

MACHLUF: Miss Ellie?

Yossi: The mother in the last two programs started getting into things.

ZEHAVA: She didn't want any unpleasantness with her daughter-in-law as if she wanted to take away her son. She promised her-she's only coming to visit him

Yossl: And on one hand she also didn't want to put off her own son.

63 ITZCHAK: On the whole, in this whole family I think the mother is the most logical and honest, who doesn't get corrupted, not by business and not by money and looks for ... behaves normally, let's call it that. And in the last sequence she really discovered what she didn't want to believe all the time about J.R and she really understood that he's not honest and the fact is she told him that: "From today I'm going to keep an eye on you, on everything you do."

CECILE: She always knew but she looked the other way as if she didn't want to believe it herself.

ZEHAVA: [Fervently] It's after all her son and she didn't want to humiliate him all the time. She looked the other way. She knew everything he was doing

CECILE: And the grandson ... in spite of the fact that she misses him and will miss him, she told her son: "If you want to bring back the child-only with his mother." In spite of missing the grandson she said: "With mother "

ADI: One can see the mother believes in her course of action. Does anybody get in her way? 
Ellen's second wedding. It should be noted that Miss Ellie's instructions, the high points of the two scenes, are retold in direct quotation by Machluf and Cecile, in order to emphasize their dramatic power.

64 Forum: The dominance Miss Ellie acquires, whereby she in effect takes over the role of both mother and father, is threatening to Yossi, who hastens to defend the father's role. This leads to a heated debate over the "real life" as pects of this issue

65 Criticism: Here Cecile stops Zehava from attacking J.R as if he were a real person by reminding everybody that they are talking about a TV show. It is one of the rare instances in which a member of the group has enough distance from the show to draw a clear distinction between real life and Dallas and thereby to relate to its qualities as dramatic genre.

66 Forum: The following is a debate between Zehava and Machluf, who is supported by Yossi on the question of whether fathers have equal rights in their children. This is, in fact, a version of the ancient conflict-between the matriarchal and the patriarchal principles - which is basic to culture and appears as a main theme in Greek tragedy (Fromm 1958). Here it is prompted by Zehava, who interprets Miss Ellie's special understanding of Sue Ellen's plight by saying that they both are mothers. 7ehava's underlying argument is that the mother-child attachment is a primordial, precultural relationship that precedes the institution of the family. Her logic is founded in a prefeminist world view: The mother has a special right to her baby precisely because of the differences between the sexes that express themselves (1) biologically and (2) in the specialization of tasks in the home. Zehava claims that productive effort gives the right to the "product" and Machluf claims that "capital investment" does. Machluf's final joke is a total distortion of her point of view. Ferninists would gladly grant equal rights to fathers provided that the men share equally in the tasks in the home

Had Yossi followed his own logic concerning the "dry law" issue (cf. note 46), wherein he argued that a judge should reward and punish according to goal-oriented effort and not unintended outcomes, he would be on the mothers side in this debate. But, in fact, his argument for fathers' equal rights is founded on the opposite logic of awarding equal parenthood to males for their modest investment. The reason is that his self-interest in this case does not lie on the side of "human" actions and intentions.
ZEHAVA: ... because she feels it as a mother. If one takes away her son, what would she feel? So, she feels that way herself and doesn't want others to suffer.

64 Yossl: You speak like a mother

ADI: Not only about the child.

ZEHAVA: I told you. I repeated it and I repeat again If he would have loved his wife and child and if he had a little brains, he wouldn't do everything he did. He wouldn't

65 CECILE: [laughs] Then there would be no Dallas.

66 ZEHAva: No, if she asks then I speak my mind, and I explain to my husband. He says why should only the mother? As if one is only on the mother's side and not the father's. This is because the mother gave birth to him, the mother suffered for him and she loves him more than the father because it's from her flesh and blood. And the father is not ... He is a tather. Okay, he loves his child

MACHLUF: It's not from his flesh?

ZFHAVA: What's that?

MACHLUF: What does it mean from his seed not from his flesh?

ZEHAVA: It's not the same thing. The mother, she suffered in birth and not the father.

MACHLUF: They [fathers] haven't got 50-50 in the child?

ZEHAVA: But the mother looked after the child when he was a baby.

MACHLUF: Forget the looking after.

Yossı: .... and thanks to whom was-[unclear]

Thanks to the father

MACHI UF: But the [in French] fabrication

[production].

CECILE: The production.

MACHLUF: The production.

Yossl: The production. Who produced it? Who produces this bottle [he holds in his hand the whiskey bottle]. The machine. But who fabricated us? [laughter].

MACHLUF: [To Zehava] If you don't plant the seed in the earth

ELIHU: This is another study.

ZEHAVA: [To Machluf] Look I always gave you a lot of respect. I never said a word

MACHLUF: Why, don't I respect you?

ZEHAVA: It's not nice... I'm only explaining the fact that you say to me 
67 Evaluation: Some members of the group deal with the question of whether Dallas is about real people by creating a dichotomy between "them" and "us." In Israel there are no such people (as those in Dallas) because, if there were they would constitute a part of the society, and that is regarded as a threat. "They" exist safely outside our norms and because they are rich, they are (1) corrupt- "They do things that we couldn't even imagine to ourselves that they could do" and (2) unhappy_ "look tor problems" (cf. note 55).

This condemnation of excess is related to the concept of the "golden mean" in Jewish tradition, which advocates moderate, unextreme behavior. In Morocco, as in other feudal societies, people knew that both having too little or having too much is bad. The landlord or king behaved differently from other people. This normative tradition, which characterizes the group here, acts as a buffer against admiring J.R. and accentuates the confrontation between the group's values and those represented by Dallas.
YossI: What does he say to you?

MACHLUF: I didn't say anything to you. You said the mother, the mother deserves more in the child, more than the father. So I said...

ZEHAVA: Yes...

MACHLUF: So I said why? It's half-half.

ZEHAVA: The mother, she gave birth to him, she [carried] him for nine months. .

MACHLUF: That's fine. In our government you [women] ask for equal rights. And you actually want 75 percent.

ADI: Later, it will be all in the tape and they'll say, "What kind of talk went on there?" [laughter].

MACHLUF: I think that people who have a lot of money, like this movie describes, everything can happen with them, even more than that

ADI: So you think there are such people in real life?

67 MACHLUF: Of course there are and there are even worse people.

ZEHAVA: Here, in Israel there are people like that?

CECILE: No, there aren't.

MACHLUF: And all this because of the money. Too much. They have too much. So much so that they do things that we couldn't even imagine to ourselves that they could do. All this because of the money.

CECILE: People who have no problems look for problems.

MACHLUF: That's it exactly

YossI: Yes, I say that the director who directed the whole series and this whole rubbish

\section{ZEHAVA: Don't blush, Yossi.}

YossI: I don't blush. He has to be quite a genius

Because he engages here a population of 100 to 200 million people, a whole population in Jordan, in Egypt, in Israel, in the whole world ...

ITZCHAK: You don't have it right

Yossl: I mean he got them hooked ... he got it into them ...

MACHLUF: He actually made the film with very limited amount of people.

Yossl: I repeat again Max, Max [Machluf]. I'm not talking about Jordan and abroad, I'm talking about here in Israel. Do notice: every second Israeli says to you Dallas, Dallas, but nobody understands exactly what happens in this Dallas. Nobody

MACHLUF: From what point of view?

YossI: From what point of view? Some people don't understand at all what and you understand, about the [Ewing] family. Whoever didn't see it from the start. 
68 Criticism. In debating the difficulties of those who produce Dallas, group members show a rather surprising degree of knowledge in regard to the TV industry, comparable to what one would expect from American viewers. The only difference is that Yossi, Cecile, and Zehava refer to the actors by their characters' names or by their screen roles, whereas Americans are familiar with the stars' names. The confusion over two different newspaper stories (one about Larry Hagman's "J.R. style" financial demands and the other about Jock's death) leads to this argument about the facts behind the scenes.

69 Interpretation, Participation: Two typical examples demonstrate how participants have no problems in systematically ignoring the interviewer's questions whenever they do not fit naturally into their conversation. In the previous exchange, Yossi brushes away Adi's question and goes on talking about the actors. Cecile here states that she is not going to answer Elihu's question elaborately by declaring. "I've got something to add" and proceeding to analyze characters.

70 Participation, Acculturation: Cecile is consistent in promoting her rich-poor stereotype (cf. notes 55,56 ). It is of great importance for a person's development to grow up in a proper family environment. Cecile's normative model of a family is made clear as the opposite to her non-normative description of Lucy's family. Lucy grew up "without a mother and a father" and therefore was not exposed to norms and thus cannot be normal, since nothing comes from nothing.

For Cecile, the "outrageous" aspect of Lucy's romance with Ray is not in the newly discovered incestuous connection "true, today he is her uncle" - but in the fact that "once he was the servant." Not considering romance with an uncle unacceptable is not surprising in that Jewish law permits marriages between uncles and their nieces.

\section{ITZCHAK: Maybe he can get used to it}

Yossl: It's not worth his while to see the second and third episode, do you see? But many people just drag along, like I say to you: "I saw a good movie in the Eden Cinema," then you also go to see that good movie. But the director is very clever, he directed it very well. He did a lot of cinema here. Do you [Adi] know what it is? A lot of colors, a lot of tricks, a lot of bluffs, a lot of

ADI: But ... the people you looked at

Yossl: The people are actors. They are allocated [parts] and they play according to

ADI: Do they play real parts or like Alice in Wonderland?

68 Yossl: Real characters. For instance, I read in the paper that they didn't find anybody to replace J.R."who killed J.R." - - read in the paper. They didn't find anybody to replace him.

THE WOMEN: No, the father

Yossl: The father, that's right.

CECILE: Jack, the father.

ZEHAVA: Jock, the father.

CECILE: Jock passed away and they wanted somebody to replace him.

\section{ELIHU: But do you know such people?}

69 CECILE: No, far, far, far from it. I've got something to add about the mother and the trial, about the child. When J.R. asked the mother if she wants the grandchild back, she refused, both as a mother and as a person who has been through the experience. She has already brought up a granddaughter without a mother and nothing much came of that. She brought Lucy up already. J.R. has already caused problems to the brother, got him out of the ranch and they accepted the daughter, and brought her up and what has become of that daughter?

\section{GIL: Not good?}

70 CFCIIF: Of course, not good. What did she have? The whole time she suffered without a mother and a father in spite of having a ranch and a grandfather and grandmother and uncles, she always felt ... who did she fall in love with and who has she been with? True, today he is her uncle but once he was the servant, Ray. She started the story with him. She was his lover. At the end when she got married it was to someone without money. She wanted something but nothing came out of this wedding as well. So she'll [Ellie] bring up a second grandchild without parents? 
71 Criticism, Interpretation: Yossi's attempt to elaborate on the idea that "it's a whole Mafia of J.R.'s" - which is unfortunately interrupted by Itzchak - recalls a theory put forward in a critical analysis of Dallas (Mander 1982), according to which the show is a serialization of a new American mythology, expressed first in The Godfather, which portrays America's social institutions as corrupt. Success can no longer be achieved by hard work but only by the power and the backing of "the family." Individuals cannot be judged as immoral because the responsibility for immorality shifts to society as a whole.

72 Interpretation: In saying that the father's criterion for supporting one of his sons was the ability to do business, Cecile demonstrates she sensed the conflict between family and business values underlying all Dallas episodes.

The blatant domination of the business principle, in J.R.'s case, which threatens to destroy the family altogether, is not remarked on explicitly in the discussion, but the surprising choice of the three women as central characters might be a clue to J.R.'s being conceived as a threat to the "normal" family order that hopefully will be overcome by the superior wisdom of the women.

73 Forum: It is evident that Yossi is bothered by the questions of why the father of the family has lost his authority over his sons, because he keeps returning to it (see his comments at notes 15, 74). Yossi wants to know why there isn't someone who takes ultimate responsibility and thus reinstates order and prevents the chaos in which each family member fights the other, leading to total destruction. Yossi is from a generation of people whose fathers were immigrants to a new country and who lost their standing in the family. Moroccan Jews who grew up in Israel were deprived of the orderly world of a traditional patriarchal family and abandoned to a world where competition is a free-for-all and not subject to established norms or to fathers' final rulings.

In spite of the fact that the discussion in this last sequence (notes 71-73) does not follow the rules of a formal debate, the different approaches of Itzchak, Cecile, and Yossi to the problems of anomie and the disintegration of the family can be analyzed. While Itzchak rejects or represses the issue by claiming that it's not the case in real life, Cecile and Yossi are not satisfied with this answer. Cecile looks for the reasons to explain the process, while Yossi gets very emotional in lamenting the loss of the father's authority. Although his statement does not formally qualify as saying "it is real," the emphatic recurring manner in which he brings this up indicates that it is relevant in his life.
ITZCHAK: On the whole, I think about this story of Dallas there might be such cases but I don't think there can be in the same family such great differences between the brothers, and one cannot imagine [them] in such a business because there are such differences: on one hand, one sees goodhearted honest people in the same family and on the other hand one sees people who cheat all the time, steal all the time, kill and do not get caught. These things are not real... It's not . .

71 Yossı: One could say Mafia

ITZCHAK: I don't think

Yossı: One can say that it's a whole Mafia of J.R.'s. A whole Mafia built in

ITZCHAK: I don't believe it can be real ... that it can happen in any country, in any place.

72 CECILE: I'll tell you why. The father always thought that Bobby is ne pas capable, is not capable, and he wanted to show him that is he is. The father always thought that J.R., J.R., J.R., J.R. He always considered Bobby from the business point of view

73 Yossl: But who brought them up? Who is their boss? Who decides here for J.R.?

CECILE: Nobody decides.

Yossi: Who has the biggest share of the money? CECILE: The father.

Yossl: The father, why then doesn't he decide for them? Why? I'm asking you — why doesn't he decide for them?

ADI: Explain to me why do they have so many problems in the family. What sort of relationships do they have?

CECILE: They don't have any brotherly ties.

ADI: Meaning?

CECILE: It's not clean, the atmosphere is not clean.

CECILE: I think the father had not a little to do with it in the beginning so J.R. follows in his footsteps. 
74 Evaluation: In quoting the Ethics of the Fathers from the Mishna, Machluf makes an appeal for Jewish norms, thereby defining himself again as Jewish in his reaction to Dallas (cf. note 10). The "middle" he refers to is the norm of the "golden mean" (cf. note 67). In looking at the psychological functions of Machluf's insistance that money causes unhappiness, it should be mentioned that Herzog-Massing (1984) has discovered that in German viewers this approach corresponds to people having serious problems in their own lives. Dallas is used by them to escape into daydreaming to comfort themselves in the notion that these people's problems are no less serious than their own.
75 Evaluation: This presentation of an alternative normative structure-which is "theirs" and not "ours" might suggest that Dallas is a vehicle for projection: All sorts of impulses that are in contradiction to lower-middle-class and Jewish norms can be projected outside of the viewers' society and onto Dallas.
74 MACHLUF: From everything I saw in Dallas, and I followed some sequences in Dallas, I came to the conclusion that a lot of money is no good for the soul. And a lot of women... Whoever has "a lot of property has a lot of worries," as it says in Pirkei Avot A person should be in the middle both in money, in honesty, in everything. We learn from the series that a lot of money - what does it cause? Even between brothers one hates the other. [Zehava and Yossi agree.]

Yossı: But Max... Why don't his father and his mother get into it? Aren't they the big shareholders?

MACHLUF: They get into it from time to time.

CECILE: The mother tries to fix as much as she can, but it's not enough.

MACHLUF: But sometimes they can't. J.R.'s influence is very great.

ADI: Does it say anything about the American society?

ITZCHAK: I don't believe

75 Yossl: Yes, Americans usually live in this way. Especially where these people live in Texas, in Dallas. This is their life and this is their way of life and everything is natural. You can see worse things there. It's the life as it is - the adultery, the bribes, the cheating, all this goes on there in Texas.

ADI: I'll ask you two more questions-then you can go to bed. The first one is-if you were the director and were told that there's no money and you had to do the last episode, what would you do to tie it together?

Yossı: We would fix J.R. so that he is put in prison. [Everybody agrees.] So that he digests it properly

ZEHAVA: So that others would also learn not to steal and not to kill [otherwise] they will pay for it.

Otherwise here in Israel, everybody will steal and murder and nothing will be done... I would like J.R. to go to prison; Sue Ellen is also not so innocent, with her adultery, and Pam I would want to be pregnant and to have a baby of her own and everything will ... ITZCHAK: You talk as an Israeli. I want to tell you one thing

MACHLUF: I've never been to America. 
76 Interpretation: Itzchak's reaction to Zehava's criticism of Sue Ellen reflects his difficulty in finding himself in a process of historical and social change where people do not behave according to the norms he has internalized and uses to assess the world. He seems to be disturbed by people in his own society who do not act according to norms - and are still not punished. As he cannot deal with this, he takes it out of his world and, as it were, describes it in the context of another-namely, Europe, where it can be "relativized."

77 Cf. "And shall I not have mercy on Nineveh the city which hath more than 120,000 people who cannot tell their right hand from their left, and many cattle?" Book of Jonah, last verse.

78 Gratification: Comparing Machluf's "I want to see it because I haven't got it" to Cecile's "I don't like the children to watch" sums up the conflict participants experience in viewing Dallas. Not to "have it" is frustrating, but to "want" or "expect" it is threatening to the group's precariously balanced normative system. In Cecile's words, "One doesn't expect anything of the story" for oneself. Wanting too much is antinormative - it stands for egoism and lust and can endanger a person's life. It is the old fear expressed in the repeated fairy tale of the fisherman's wife.

79 Moked ("Focus") and Mabat Sheni ("A Second Look") are current affairs programs on Israeli Television

80 Gratification: Cecile is expressing the classic, often-criticized function of television - that it is an escape from reality. As this conversation was taped in February 1983, when the Israeli army was in Lebanon during what could be described as a war of attrition, the reality in this case is not humdrum and routine but anxiety-provoking and tense.
76 ITZCHAK: The word "adultery" in Israel is still a little important but not in Europe. There it's something completely normal. That means one cannot judge a woman because she was unfaithful; the court would not take it seriously. She did not commit a crime against the law. You talk as a Jew. In a religion like the Jewish faith a wife is not allowed to commit adultery because she is not a wife then. But in Europe

AdI: Why do you look at Dallas? Why do you watch Dallas?

CECILE: It's not better or worse than another series There is no choice [in programs] here. Also all the beautiful things which one sees-the ranch and the richness. That's why one views; one enjoys watching, but no more. One doesn't expect anything of the story.

MACHLUF: The film is made out of sequence after sequence, and each is a sequence in itself. In every sequence you see the beginning and the end. Within this they show you the life of Americans.

CECILE: So you're answering the first question-that this is how you imagine America.

77 MACHLUF: .... the richness in America, the luxury And it's foreign for me and we love to see it. The private pools, the elegant dress. I live in 64 square meters and there [they have] kilometers and kilometers. And cows. And everything. I want to see it because I haven't got it.

78 Cecile: I, on one hand, don't like the children to watch

79 Yossi: The Israelis love this series because it was the only one in color in the beginning [general laughter]. I don't like Dallas but I prefer this over Moked or some Mabat Sheni, or some concert.

80 CECILE: I'll tell you. For me it brings a change. I don't know if that's true for everybody. I, for instance, here in Israel, am fed up with the war and with what there is in the news and what there is every day - this one was killed and that one was something else. This way one sees a more quiet life, in this sense. Then we also can think of different kinds of problems. 


\section{Conclusions}

Although the larger study will compare fifty such conversations, the richness of this one example is enough to suggest a number of "conclusions"

(1) The group clearly understands the basic narrative, unimpeded by subtitles and cultural differences. Their focus on primordial passions and the patterns of interpersonal relations may conceal a lesser understanding of the intricate machinations of a particular subplot (cf. note 18, where the meaning of the secretary's phone call to the restaurant is misunderstood). The universality of these elemental relationships seems to be a key to the ease with which the program is understood.

(2) Retelling of the narrative by group members is in an interpretative and evaluative mode. They edit the story as if it were more "linear" than it is on the screen by stringing together the segments of only one of the main themes, and they treat it as if it were leading to a final "resolution" rather than to a never-ending and potentially reversible serial. They are certainly closer to Tannen's (1982) Greek storytellers, who define their task as telling an interesting story, than to her Americans, who try to be as detailed and precise as possible even at the expense of being boring.

(3) Their reediting of the story invokes a moral frame, whereby the plot rewards and punishes characters according to the moral or immoral motives that are attributed to them. Approval of a character entails attribution of an intrinsic moral motive to explain action. Our Moroccan viewers would surely disagree with Arlen's (1980) proposal that the fascination of Dallas is its moral improvisation and equivocation and its consequent unpredictability. Their reading is more lawful, their characters less ambiguous. That Sue Ellen discovers true love with Dusty (note 55) may not be in the text; it is in the reading. The story may be anomic; this reading is not.

(4) It is likely, therefore, that the program serves as more of a "forum" (Newcomb and Hirsch 1984) for Israeli Moroccans than for Americans. The constant "negotiation" between their own values and those of the program leads the group to commute between discussion of the program and discussion of "life." The conversation is replete with references to issues of family, sex roles, justice, standards of living, and the like. On the basis of issues raised in the discussion of the program, reference is made to social relations within the immediate group itself, to personal relations in the community of group members, to problems of Israeli society, to American society (where Dallas is often treated as equivalent to America), and to philosophical issues more generally.
(5) The reciprocal of "forum" is "critical distance, that is, discussion of the program as genre, as formula, as a story governed by "poetic" rules and not necessarily related to "life." There is not so much of this sort of distancing on display in the present discussion. Occasionally, however, there is a flash of poetic insight, as when the concept of "Mafia" is alluded to (note 71), echoing the critical analysis by Mander (1982), who argues that Dallas is a version of the newly prevalent Godfather myth in America. Strong emphasis is given by the group to the "escapist" functions of the program_-in giving relief from the strictures of religious observance, the constriction of living quarters, and the terrible strain of the long Lebanese campaign. Interchanges of this kind, we surmise, are another of the keys to the process whereby American television programs penetrate linguistic and cultural frontiers. People help one another to decode them. The same interchanges, we believe, constitute the filters through which the story-as hero, metaphor, message-makes its way into the culture.

(7) The group, of course, has dynamics of its own, and if certain roles emerge during the course of the conversation, and even if certain members are more dominant than others, this may well be an accurate simulation of everyday television talk. If Machluf prevails in his view, the group may well refuse entry of the values of the program into their lives as traditional Jews, if Yossi prevails, the program is altogether unworthy of serving as a "forum" for discussion of real problems. Among the roles engendered by the discussion, one can discern that of "commuter" (triggering transitions between the story and real life) and "resource person" (providing details from past programs).

George Gerbner may be right in asserting that the effects of television are best studied by asking people not about television but about life. We add only that in discussing television, people often find themselves discussing life. 


\section{Acknowledgment}

Dean Peter Clarke of The Annenberg School of Communications, University of Southern California, and the Trustees of The Annenberg School deserve our thanks for their generous support of this project.

\section{References}

- Arlen, M

1980 Smooth Pebbles at Southfork. In Camera Age: Essays on

- Barthes, R

Television. New York: Farrar, Straus \& Giroux. Pp. 38-50.

1975 S/Z. New York: Hill and Wang

- Bennett, A

1978 Interruptions and the Interpretation of Conversation. In Proceedings of the 4th Annual Meeting of the Berkeley Linguistics Society. Berkeley: The Department of Linguistics,

- Berger, A. A.

1981 Media Analysis Techniques. Beverly Hills: Sage

- Booth, W. C.

1982 The Company We Keep: Self-Making in Imaginative Art, Old and New. Daedalus (Fall):33-59.

- Brown, P. and S. Levinson

1979 When Is an Overlap Not an Interruption. In Questions and Politeness: Strategies in Social Interaction. E. N. Goody, ed. Cambridge; New York: Cambridge University Press.

- Bryce, Jennifer W., and Hope Jensen Leichter

1983 The Family and Television: Forms of Mediation. Journal of

- Fromm, E. Family Issues 4:309-328.

1958 The Forgotten Language. New York: Grove Press
- Hall, Stuart

1980 Encoding and Decoding of Television Discourse. In Culture Media and Language. S. Hall et al., eds. London: Hutchinson.

- Herzog-Massing, Herta

1984 "Dallas" Among German Viewers with a Comparison of "Denver Clan"- A Pilot Study. Unpublished report.

- Katz, Elihu, and Tamar Liebes

1984 Once Upon a Time, in Dallas. In Inter Media, International Institute of Communication, May 1984, 12(3):28-32.

- Lull, J.

1980 The Social Uses of Television. Human Communication Research 6:197-209.

- Mander, M.

1983 Dallas: The Mythology of Crime and the Moral Occult. Journal of Popular Culture 17 (Fall):44 48

- Merton, Robert

1946 Mass Persuasion. New York: Harper.

- Morley, Dave

1980 The Nationwide Audience. London: BFI.

- Newcomb Horace

1984 On the Dialogic Aspects of Mass Communication. Critical Studies in Mass Communication 1(1):34-50.

_, and Paul M. Hirsch

1984 Television as a Cultural Forum. Quarterly Review of Film Studies.

- Tannen, D.

1982 Spoken and Written Language: Exploring Orality and Literacy. Vol. IX in the series Advances in Discourse Processes. R. Freedle, ed. Norwood, N.J.: Ablex.

- Thomas, Sari, and Brian P. Callahan

1982 Allocating Happiness: TV Families and Social Class. Journal of Communication 32(3):184-190. 